\title{
Sampling blockchain-enabled smart city applications among South Korea, the United States and China
}

\author{
Soomin Kim ${ }^{\mathrm{a}, *}$, Ailing Zhang ${ }^{\mathrm{b}, *}$, Ruizhi Liao ${ }^{\mathrm{b}, \mathrm{c}, * *}$, Wenjun Zheng ${ }^{\mathrm{d}}$, Zhixian $\mathrm{Hu}^{\mathrm{d}}$ and Zhenglong Sun ${ }^{\mathrm{d}}$ \\ a School of Management and Economics, The Chinese University of Hong Kong, Shenzhen, China \\ E-mail: soominkim@link.cuhk.edu.cn \\ ${ }^{\mathrm{b}}$ School of Humanities and Social Science, The Chinese University of Hong Kong, Shenzhen, China \\ E-mails: ailingzhang@link.cuhk.edu.cn,rzliao@cuhk.edu.cn \\ ${ }^{\mathrm{c}}$ Shenzhen Key Laboratory of IoT Intelligent Systems and Wireless Network Technology, China \\ ${ }^{\mathrm{d}}$ School of Science and Engineering, The Chinese University of Hong Kong, Shenzhen, China \\ E-mails: wenjunzheng@link.cuhk.edu.cn,zhixianhu@link.cuhk.edu.cn,sunzhenglong@cuhk.edu.cn
}

Received 22 November 2021

Accepted 11 January 2022

\begin{abstract}
Blockchain technology is valuable due to the renowned characteristics, such as immutability, security, and transparency. Although blockchain's effectiveness and efficiency are yet to be proven, its potential for resolving social issues is attracting the attention of public administrations, private entities, and individuals to adopt or develop this technology. In this paper, some of the most high-profile blockchain-enabled smart city applications in South Korea, the United States and China are sampled and reviewed. The goal is to explore blockchain-related regulations or legislation in each country, which is the underlying basis to allow the blockchain pilots to proceed. Then, each country's key blockchain initiatives are explored using a top-down framework (i.e., central/federal government - provincial/state governments - city governments). Lastly, by summarizing those blockchain-based smart city projects, the challenges and observations are discussed.
\end{abstract}

Keywords: Blockchain, smart city

\section{Introduction}

Immutability, security, and transparency, these three characteristics, make blockchain valuable for public and private institutions. Thus, there has been considerable anticipation for the offerings that blockchain can bring about as a unique technology to solve social issues, and deal with security issues that many public and private institutions face.

As blockchain is a newly introduced technology, supports from public institutions and governments are vital: e.g., launching blockchain-based pilot initiatives for citizens to take advantage of blockchain-based services. Meanwhile, enacting blockchain-related legislation is also very important. Regulatory authorities are concerned about the misuse

\footnotetext{
${ }^{*}$ S. Kim and A. Zhang are co-first authors.

** Corresponding author. E-mail: rzliao@cuhk.edu.cn.
} 
of blockchain in tax evasion, money laundering, or uncontrollable flows of funds. Steven Mnuchin, the former US Secretary of the Treasury, mentioned that the US would regulate money flows under the Bank Secrecy Act to avoid the financial innovation endangering financial stability [8].

According to a report, due to strict regulations, 33 blockchain projects were called off after completing their pilot stages [22]. Private and public institutions need reliable evidence that blockchain is an effective and efficient technology. To provide such evidence, introducing wide-range blockchain-based initiatives is a justified way.

The main purpose of the paper is to explore blockchain-related initiatives and projects in South Korea, the United States and China. By doing so, we can learn the government's attitude over the blockchain developments. These three countries are selected for the following reasons.

First, South Korea is a potential leader in the blockchain market, because its central and local governments are actively adopting the blockchain technology. According to a United Nations E-Government survey, South Korea achieved the highest E-Government Development Index (EGDI) in Asia, which is assessed by the online service index, the telecommunication infrastructure index, and the human capital index [34]. In other words, public institutions in South Korea have firmly established their infrastructure and are prepared to implement blockchain-based projects.

Secondly, the United States is a current leader of blockchain [38]. According to a blockchain market size report, North America - the United States and Canada possess the largest share in the entire blockchain market ( 40\%) [14]. As the United States is the blockchain leader, examining how the United States develop and use blockchain is absolutely necessary. The current leader's activities - regulation and technological advancement - can be an essential reference for followers.

Last, China is also considered as an active leader in the blockchain industry. According to a report from the World Intellectual Property Organization (WIPO), in 2017, China filed more than a half of blockchain patent applications (56\%), followed by the United States (22\%) [10]. On the other side, the Chinese government has been actively adopting and encouraging blockchain related technologies. Multiple blockchain-based services, e.g., blockchain financial platforms and insurance platforms, have been fostered. Moreover, the National People's Congress of China enacted the Encryption Law in October 2019, which provided guidelines for the management and supervision of blockchain-related activities [49].

The rest of the paper is organized as follows. First, the section of "Localized comparison and categorization of projects" reviews and categorizes relevant smart city projects in South Korea, the United States and China. Then, the section of "Remarks on the reviewed applications" summarizes the features of the reviewed projects. Finally, the section of "Conclusions" concludes the paper by looking into the future challenges.

\section{Localized comparison and categorization of projects}

\subsection{South Korea}

In 2018, the Korea Institute of Science and Technology Evaluation and Planning (KISTEP) analyzed that the current technological advancement of blockchain was not pragmatic in South Korea. KISTEP pointed out blockchain's low performance in terms of the transaction rate. Meanwhile, KISTEP also expected blockchain to bring about numerous positive effects, citing that blockchain would be a radical innovation that could affect numerous industries [26]. Before introducing initiatives of public institutions, here are the blockchain laws and regulations in South Korea.

- The surging Bitcoin investment triggered attention from the central government toward cryptocurrency, which initiated a revision on the relevant legislation. For example, the National Assembly of South Korea passed "Act on specific financial information concerning the prevention of money laundering" [23].

- The National Tax Service passed a judgment that when Bitcoin is traded as goods, the traders need to pay value-added tax [1].

- The Ministry of Economy and Finance concluded that it is a violation of Article 8 of the Foreign Exchange Transactions Act if a firm uses Bitcoin to transfer money overseas without an authorized financial institution's involvement [1]. 


\subsubsection{Central government of South Korea}

The central government of South Korea focuses on validating the effectiveness of blockchain, e.g., initiating blockchain-based pilot projects in public institutions. It expects that the projects will boost the productivity of various industries and solve social issues. Two observations are made as follows.

First, the central government focuses on applying blockchain-related technologies in public institutions. For example, in 2020, the Ministry of Science \& ICT and Korea Internet Security Agency (KISA) nominated 24 companies to start ten blockchain-based pilot projects with an investment up to 5.3 million US dollars [27].

In addition, the emphasis has also been laid on developing blockchain-based financial technology. The Presidential Committee on the Fourth Industrial Revolution announced blockchain-related policies in 2018. The central government encouraged to integrate blockchain with financial technology. To be specific, the committee pointed out four significant limitations [36].

(1) Limitation of selective investment: South Korea developed its major industries through selective investment, e.g., telecommunication, car or shipbuilding. However, this investment method could not maintain the market share of major industries, and was inefficient on fostering new industries (market share: car: $5.2 \rightarrow 3.8 \%$, shipbuilding: $36.2 \rightarrow 20 \%$ ). The central government of South Korea recognized the necessity of extending investment strategies to newly introduced technologies, e.g., blockchain.

(2) Lack of interest in inclusive growth: inclusive growth can encourage industrial growth while solving social issues simultaneously. In 2016, the entire amount of research and development cost in South Korea was about 16 billion US dollars, while social issues oriented research accounted for only $10.5 \%$. The committee recognized that it is vital to increase investment in research and development, especially in inclusive growth.

(3) Large corporate oriented policies: the central government often provided favorable policies on innovation for the governmental entities and large conglomerates, while there was a lack of interest in small and mediumsized enterprises (SMEs).

(4) Inadequate infrastructure for sustainable growth: South Korea did not establish a system that encouraged or supported people who failed at their business to restart. As a result, more people preferred stable jobs.

\subsubsection{Government ministries of South Korea}

In 2020, ten projects were initiated as pilots applying blockchain to public sectors [27]. The key features of the 10 projects are summarized in Table 1 .

Table 1

Blockchain-related projects of South Korea government ministries

\begin{tabular}{|c|c|c|}
\hline Government Agencies & Project & Remarks \\
\hline National Police Agency & Data immutability & $\begin{array}{l}\text { Protect the reliability and the integrity of } \\
\text { digital evidence in each step }\end{array}$ \\
\hline Rural Development Administration & Traceability of agricultural product & Ensure the credibility of products' information \\
\hline Ministry of Health and Welfare & Identifying eligible beneficiaries & Manage welfare benefits distribution \\
\hline Korea Expressway Corporation & Toll fee management & $\begin{array}{l}\text { Automatically and transparently audit drivers' } \\
\text { records }\end{array}$ \\
\hline National Election Commission & Data immutability & $\begin{array}{l}\text { Maintain transparency and credibility of } \\
\text { election }\end{array}$ \\
\hline $\begin{array}{l}\text { Ministry for Food, Agriculture, } \\
\text { Forestry and Fisheries }\end{array}$ & Security and traceability & $\begin{array}{l}\text { Secure the recorded log and trace the possible } \\
\text { contamination sources more quickly }\end{array}$ \\
\hline $\begin{array}{l}\text { Ministry of Land, Infrastructure } \\
\text { and Transport }\end{array}$ & Documentation and certification & Avoid cumbersome bureaucratic process \\
\hline Ministry of Foreign Affairs & $\begin{array}{l}\text { Data immutability and document } \\
\text { authentication }\end{array}$ & $\begin{array}{l}\text { Improve the apostille efficiency by issuing } \\
\text { immutable electronic documents }\end{array}$ \\
\hline Korea Customs Service & $\begin{array}{l}\text { Link data between online shopping } \\
\text { platforms and Korea Customs }\end{array}$ & $\begin{array}{l}\text { Simplify the current clearance procedure and } \\
\text { shorten waiting time at customs }\end{array}$ \\
\hline Ministry of Oceans and Fisheries & Documentation and certification & Streamline the shipping process \\
\hline
\end{tabular}




\section{(1) National Police Agency}

As the cases of cybercrime surged, digital evidence and digital forensic are critical. In each step of litigation and investigation, maintaining the source integrity is vital to validate the admissibility of evidence. In other words, the steps of an investigation (confiscating digital evidence $>$ sorting $>$ analyzing $>$ reporting $>$ sending $>$ discarding) need to be transparent and credible. This project aims to utilize blockchain technology to protect the reliability and the integrity of digital evidence in each step. The execution team of the project also believes that this blockchainbased platform will ensure transparency of the investigation process.

(2) Rural Development Administration

As more people are concerned about food safety, they would like to have the information of agricultural products along each link of the supply chain. The Rural Development Administration plans to track all crops' distribution processes and record the data on a blockchain-based platform to ensure the credibility of products' information.

(3) Ministry of Health and Welfare

The number of people receiving welfare benefits is larger than ever. The amount of welfare benefits that they received has also steadily increased. Along with this, the cases of fraudulent claims, e.g., people who are not eligible to receive the welfare benefits or people who receive the benefits twice, consistently happened. The Ministry of Health and Welfare will launch a platform that manages essential information for identifying eligible beneficiaries. The project's execution team expects a significant cost reduction of the administrative process for managing information for welfare beneficiaries and minimizing intermediary intervention.

(4) Korea Expressway Corporation

Korea Expressway Corporation detected an inefficient process to check toll fee reports of drivers. In response to its issue, the corporation plans to adopt a blockchain-based toll fee management system to automatically and transparently audit drivers' records.

(5) National Election Commission

In order to maintain elections as transparent and credible as possible, the National Election Commission plans to launch a blockchain-based online voting platform, through which every voter or candidate of the election can directly access the results. The voting platform is currently open to and being tested by a number of approved organizations.

(6) Ministry for Food, Agriculture, Forestry, and Fisheries

According to food supervision regulations, the entire meat production process should be recorded in the livestock $\log$ system. However, there are risks of server failure or cyber-attacks on the centralized log system, resulting in a total loss of the recorded data. For instance, when contaminated meat was sold and spread to various provinces, it would be very time-consuming for regulators to identify the possible culprits through tracking the whole supply chain. By utilizing blockchain, the Ministry aims to secure the recorded log data and trace the possible contaminated sources within a few minutes.

\section{(7) Ministry of Land, Infrastructure, and Transport}

In order to get a mortgage for purchasing a house, citizens have to visit various offices and go through relevant procedures. By utilizing online blockchain-based documentation and certification services, citizens do not have to go through such cumbersome bureaucratic processes.

\section{(8) Ministry of Foreign Affairs}

Before submitting official documents to other countries' institutions, citizens need to bring the documents to be apostilled by the Ministry of Foreign Affairs. The current apostille process takes up to 14 days. The Ministry of Foreign Affairs plans to build a blockchain-based platform to check the documents' authenticity and issue immutable electronic documents, which can improve the efficiency of the apostille process. 


\section{(9) Korea Customs Service}

With the increase in cross-border shipping, the time delays at customs have also amplified. Goods may stay at customs for several days. The Korea Customs Service is piloting a blockchain-based declaration system that will coordinate with global online shopping platforms. The system will automatically register South Korea-bound products into the blockchain-based declaration system. The introduction of the blockchain declaration system is expected to simplify the current procedures and shorten the waiting time of goods at customs.

\section{(10) Ministry of Oceans and Fisheries}

Each container requires a different trans-shipping service. However, most parts of the shipment processes is still offline-based. Therefore, managing those tasks requires intensive manual paperwork operations. The Ministry of Oceans and Fisheries aims to manage the shipping or trans-shipping paperwork through a unified blockchain platform to streamline the entire shipping process.

\subsubsection{Provincial governments of South Korea}

Reckoning the limitations of the 3rd industrial revolution in South Korea, the central government realized the importance of relaxing regulatory hurdles. However, the government cannot just deregulate blockchain without concerns of blockchain's misuses being properly addressed. Thus, the central government supports provincial governments to test blockchain-based smart city projects. Some projects are currently under construction and their key features are summarized in Table 2.

Seoul-si Seoul, the capital city of South Korea, is constructing several pilot projects with an investment of 108 million US dollars to establish a blockchain-enabled smart city in five years. Seoul focuses on the government transparency and citizen convenience. Here are the current blockchain projects that Seoul has initiated [50].

(1) Blockchain-based work contract

Some employers tend to avoid official work contracts with workers to evade taxes. For example, employers offer private contracts while paying slightly more to the workers. Without official work contracts, the workers are not entitled to receive unemployment benefits and the other four primary insurances, i.e., National Pension, National Health Insurance, Worker's Compensation, and Welfare Service. Seoul city tackles this issue through blockchain,

Table 2

Blockchain-related projects of provincial governments

\begin{tabular}{|c|c|c|}
\hline City (si)/District (do) & Project & Remarks \\
\hline \multirow[t]{7}{*}{ Seoul-si } & Blockchain-based work contract & Guarantee workers to receive all legal welfare benefits \\
\hline & Blockchain-based used car sales platform & Provide a transparent platform that prevents customers from overpaying \\
\hline & Electronic contract for construction workers & Guarantee construction workers to receive the right amount of wages \\
\hline & mVoting & Provide a transparent online voting platform \\
\hline & Document management platform & $\begin{array}{l}\text { Provide a blockchain-based platform that stores citizens' documents for } \\
\text { verification }\end{array}$ \\
\hline & S-Coin & $\begin{array}{l}\text { Cryptocurrency for public services, e.g., public transportation and tax } \\
\text { payment }\end{array}$ \\
\hline & Seoul Citizen Card & Provide a blockchain-based identity card \\
\hline \multirow[t]{3}{*}{ Jeju-si } & Citizen identity verification & $\begin{array}{l}\text { Help local merchants to sell duty-free goods to eligible customers and } \\
\text { help tourists to get tax refunds quickly }\end{array}$ \\
\hline & EV battery management system & Provide credible data regarding EV batteries \\
\hline & Tracking carbon usage & Record citizens' energy consumption, which can be used to exempt taxes \\
\hline Gangwon-do & Blockchain and AI based healthcare & $\begin{array}{l}\text { Users' health data are securely recorded and analyzed by AI to assist } \\
\text { doctors' diagnosis }\end{array}$ \\
\hline \multirow[t]{2}{*}{ Busan-si } & Decentralized identifier & DID enables citizens' access to public services in a secured way \\
\hline & Water quality system & Provide credible data on the current water quality \\
\hline Jeollabuk-do & Cryptocurrency ecosystem & Provide a safe and commissionless cryptocurrency ecosystem \\
\hline
\end{tabular}


which requires all labor contracts to be signed in the blockchain system that enables the city administration to check whether the employers have issued official contracts quickly.

(2) Blockchain-based used cars sales

Janganpyeong is a local hub that clusters many used-car sales companies. Over the past years, many customers complained for overpaying low-quality used cars due to the lack of transparent information or a unified sales platform. In response to that, a blockchain-based Janganpyeong Automotive Centre was built, which aimed at providing customers with transparent and immutable information of used cars to boost trust among customers and merchants.

(3) Electronic contract for construction workers

In the past, Seoul cooperated with construction companies and job agencies for regulating laborers' wages. In the model: first, the Seoul city releases labor-wage funds to construction companies; the companies then pass the money to job agencies; the job agencies then transfer wages to workers. This process has been problematic because either construction companies or job agencies might pay the workers less than what they should get. To ensure transparency of paying the workers' wages, Seoul has initiated a "Money-electronic-direct-system". By using blockchain, the regulatory department of Seoul city can check whether workers are paid with the right amount of wages or not.

\section{(4) mVoting}

The Seoul city encourages citizens to participate in its policy-making process. Online voting can be one of the most valuable tools to attract the citizens' active participation. However, online voting systems are vulnerable to the fabrication of the voting results. The city government of Seoul created a blockchain-based voting platform called mVoting. Since its roll-out in 2014, mVoting has been used to collect people's ideas without any risk of being manipulated. mVoting is collecting ideas regarding city-operated projects, education policies, and other policies. According to the report of ' 2020 mVoting performance and its current status', about 1.12 million users have participated in 3.01 million online voting activities, cumulatively. Out of 8,294 voting issues, 2,642 voting issues have been policy-related [40].

(5) Document management platform

Citizens sometimes need verified identification to access public services, which means that citizens need to bring numerous documents and visit several public institutions. Seoul plans to provide a blockchain-based platform that citizens can securely store their documents online. The Seoul city expects this platform to mitigate the traditional verification process.

(6) S-Coin

Seoul created a cryptocurrency payment platform for public transportation. Seoul plans to expand its use to other public services, e.g., citizens can pay tax through S-Coin, and Seoul can give low-income citizens subsidies [48].

\section{(7) Seoul Citizen Card}

Similar the documentation platform mentioned above, some public services can only be accessed before verifying the users' identities. However, it is possible to forge the current identity card in South Korea. Therefore, the Seoul city initiated a blockchain-based identity card. It aims to faithfully verify the citizen identity, and also to shorten the verification process. The Seoul Citizen Card was firstly applied to the Seoul journalist community, through which, people or institutions who are to be interviewed can verify whether the interviewer is a true journalist or not.

$J e j u$-si Jeju Island's government believes that experiencing blockchain services is the fastest way for citizens to get familiar with the concept of blockchain. Thus, Jeju Island focuses on providing blockchain-based public services [32]. The pilot projects in Jeju Island are reviewed below.

(1) Citizen identity verification

Thanks to Citizen Identity Verification, merchants can check whether a customer is eligible to purchase duty-free goods without any burdensome process. This service can help merchants sell duty-free goods to eligible customers and help tourists get tax refunds at customs conveniently. 


\section{(2) Battery management system}

Battery management of electric vehicles $(\mathrm{EV})$ is essential for longer battery utilization and also battery reuses. However, the history of EV battery reuses face the possibility of forgery and alteration. Therefore, it is necessary to have credible data in the whole life cycle of EV batteries. For that reason, standards for used EV batteries are required. The EV battery management system is to build a blockchain-based platform for managing the distribution history of EV batteries, which aims to standardize the processing of used EV batteries and also integrate reliable data regarding the used EV batteries.

(3) Tracking carbon usage

Jeju Island is highly committed to achieving the goal of reducing carbon emissions. It encourages citizens to lead an environment-friendly lifestyle that is conducive to achieving the carbon goal. Therefore, Jeju Island plans to launch a blockchain-based energy usage platform. The platform holds the records of citizens' energy-saving activities, and those records can be used to exempt taxes.

Gangwon-do Gangwon plans to provide a blockchain and artificial intelligence (AI) enabled healthcare service. The users' health records will be retrieved and analyzed using AI algorithms to assist doctors in diagnosing and treating patients, and the blockchain based platform will securely store users' health data and doctors' prescription.

\section{Busan-si}

\section{(1) Decentralized identifier}

In 2020, Busan launched a blockchain-based smart card for identity verification - Decentralized Identifier (DID), which can help citizens to access public services, e.g., receiving government benefits or visiting certain buildings. DID-based services can be used both online and offline. Either way it is used, the blockchain based platform can secure users' privacy and also prevent information leakage to unauthorized parties [31].

(2) Water quality system

Despite the provisions put in place by the city administration to ensure the water quality, some citizens still do not trust it. To address this, in 2020, the Busan city created a blockchain-based IoT platform, which allows citizens to check the water quality directly [25].

Jeollabuk-do Within the Jeollabuk district, there is a famous Korean traditional village that attracts many tourists, called Jeonju. The district has established a cryptocurrency ecosystem, with which tourists can purchase food and souvenirs in Jeollabuk. Both tourists and merchants welcome the initiative due to fund safety and commissionless transactions.

\subsection{The United States}

\subsubsection{Federal government of the United States}

The US federal government has a decent level of interest in the adoption of blockchain technology [9]. However, the relevant regulatory department has expressed concerns that virtual currency, especially cryptocurrency, carries risks such as jeopardizing financial stability, tax evasion, or money laundering. To address these concerns, several ministries of the federal government are developing or enacting necessary regulations. The current status of laws and regulations regarding blockchain at the Federal Government level in the United States is presented below [5].

(1) The Internal Revenue Service (IRS) now considers virtual currency as one of the new form of assets, which implies that all transactions involving virtual currency should be subject to taxation.

(2) The US federal regulator, the Commodity Futures Trading Commission (CFTC), defined virtual currency as commodities under the Commodity Exchange Act.

(3) Another US federal regulator, the Securities and Exchange Commission (SEC), defined virtual tokens as securities under the Securities Act of 1933 and the Securities Exchange Act of 1934. In other words, all cryptocurrency transactions and investments should observe the regulations of US Federal Securities. However, virtual currency is being still defined as distinct from fiat money or even e-money. 
Table 3

Blockchain-related projects of state governments

\begin{tabular}{|c|c|c|}
\hline States & Project & Remarks \\
\hline Delaware & Delaware Blockchain Initiative (DBI) & $\begin{array}{l}\text { Delaware was one of the first-movers to adopt blockchain. However, DBI came into a } \\
\text { halt due to the fundamental limitation of blockchain. }\end{array}$ \\
\hline \multirow[t]{3}{*}{ Illinois } & Document verification & Blockchain-enabled document verification platform. \\
\hline & Property title registration & Protect and manage property transparently. \\
\hline & Energy usage tracking & Encourage and incentivize the consumption of renewable energy. \\
\hline \multirow[t]{2}{*}{ Vermont } & Insurance management platform & Reduce insurance costs by lowering fraud risks and shortening insurance claiming time. \\
\hline & Property title registration system & Reduce bureaucracy and provide transparency. \\
\hline Wyoming & Digital assets-existing law & Consider digital assets as valued assets equal to cash. \\
\hline New York & Health tracking system & Manage users' COVID-19 test results, as well as vaccination history. \\
\hline California & Blockchain-based municipal bonds & $\begin{array}{l}\text { Increase the bond liquidity and facilitate the direct investment on government projects } \\
\text { using the municipal bonds. }\end{array}$ \\
\hline
\end{tabular}

(4) The Federal Reserve System (FRB) reviews the possible impacts on the currency system in the case of adopting cryptocurrency [13]. FRB launched the "Fast Payments Task Force" to examine improvements required in wire transfer and payment systems.

\subsubsection{State governments of the United States}

Many states in the US have enacted laws regarding the usage of blockchain and initiated blockchain-related pilot projects in their public services. Some of the high-profile projects are reviewed below and summarized in Table 3.

Delaware Among state governments, Delaware is considered as one of the first-movers to adopt blockchain. As over $66 \%$ of the Forbes 500 companies are headquartered in the state, Delaware always pays close attention to the latest technological developments, e.g., blockchain. Delaware envisions that blockchain technology can further facilitate the companies' operations. The state rolled out Delaware Blockchain Initiative (DBI) and divided the initiative into three stages [41].

The first stage was to adopt the distributed ledger technology at the Delaware Public Archives, where documents would be recorded on a blockchain-based system that stored data without the risk of being tampered with.

The second stage was to adopt smart Uniform Commercial Code (UCC) based on blockchain. Because the traditional paper-based UCC filing process has been deemed inefficient and prone to errors.

The third stage was to make distributed ledger systems completely transparent. By integrating blockchain with distributed ledger systems, the state government, institutions, and citizens can access the distributed ledger without limitations of place or time. The state government of Delaware aims to eradicate the risks of accidental and intentional data tampering.

However, as a first-mover, Delaware faced the technological limitation of blockchain - a low speed of processing simultaneous transactions, which is a known problem for current blockchain-based systems. In 2018, the state government of Delaware decided to end the DBI project. The reason was that the state government's expectations to streamline operations of both state administration and companies were not fully realized [15].

Illinois Illinois is among the states that showed a significant interest in utilizing blockchain technology to their governance systems. In 2017, the state government of Illinois initiated several blockchain-based pilots. Studies undertaken by the government of Illinois showed positive results of the introduced blockchain services, although the government also concluded that the Proof-of-Work (PoW) - a method of blockchain - is inefficient [24].

(1) A blockchain-based platform that can check various kinds of documents, e.g., insurance, certificate of physician credentials, or citizen's digital identity.

(2) By registering citizens' property titles on a blockchain-based platform, the state government of Illinois can thoroughly and transparently protect and manage citizens' property.

(3) The state government of Illinois created a blockchain-based energy usage tracking system, which aims to accurately record the renewable energy usage by citizens and companies. The state government also planned 
to give incentives to citizens or companies who contributed to environment protection according to the renewable energy usage record.

Vermont In 2018, an act regarding blockchain business became legal, and two pilot projects were launched in Vermont [37]. The Act created a new type of business - Personal Information Protection Company (PIPC), which manages personal data for business purposes. The Act stresses that PIPC must protect personal information from being leaked.

Moreover, Vermont initiated two blockchain pilot projects: an insurance document management platform and a blockchain-based land registration system. The blockchain-based insurance project aims to reduce insurance costs by reducing the risk of insurance fraud (i.e., using credible and immutable data) and shortening the insurance claim time (i.e., using condition-controlled smart contracts).

Burlington, Vermont initiated a blockchain-based property title registration system to streamline the property title registration process. The traditional system for title registration was a long and tedious process: the deed rendered to the property registry office; then, the documents copied, stamped and returned to the agent; finally, the agent recorded a copy of the documents and then passed the documents to the buyer. In the proposed new system, the deed's copies can be saved on blockchain, which will be done in cooperation with the Burlington government for scanning, hashing and storing all documents. All people or corporate representatives who are involved in property transactions can access relevant documents [2].

Wyoming In 2019, Wyoming enacted a law, referred to as SF0125: digital assets-existing law [21]. The law received wide attention, which is because, according to its proposition, digital assets (e.g., cryptocurrency) are given super-negotiability protection in Wyoming. In other words, digital assets are being considered as valued assets equal to cash. As UCC filings are considered as "uniformed federal law", Wyoming needs to figure out how to maintain the standard code, which will eventually succeed in matching the digital assets with UCC categories.

SF0125 actually covers the entire spectrum of digital assets and divides them into digital consumer assets, digital securities, and virtual currencies [6].

(1) First of all, digital consumer assets mean that citizens can purchase a product with the digital asset as they did with the cash. Wyoming is the first state that distinctively defines the utility token as a type of digital asset.

(2) Secondly, digital securities are digital assets that constitute securities, while excluding digital consumer assets and virtual currency.

(3) Lastly, IRS has already defined that virtual currency is a medium of exchange. However, IRS concluded that the virtual currency is not recognized as a legal tender by the United States government [39]. Since SF0125 and UCC, virtual currency has super-negotiability, people and organizations can transfer the virtual currency without any problem.

New York In the context of the COVID-19 pandemic, the New York City of the New York state initiated a pilot service that can track individuals' health status, especially aiming at protecting people in gathering places, such as theatres or stadiums. This service manages users' COVID-19 test results, as well as vaccination history, which can be used to facilitate users' access to theatres or stadiums. New York City expects this service can help to prevent the virus spread and boost the city economy [3].

California Berkeley, California, is the first administrative region that issued its municipal bond through cryptocurrency [12]. Berkeley expects that this will solve fundamental issues of traditional municipal bonds: poor liquidity, and complicated conditions. Moreover, Berkeley expects people to become more interested in municipal projects and directly invest in government-funded projects using government-backed cryptocurrency. Burlington of Vermont, Lawrence of Kansas and Cambridge of Massachusetts also have started to adopt similar municipal bonds [28].

\subsection{China}

Although the Chinese government has been strictly monitoring the use of virtual currency, it has been actively supporting the development of blockchain applications. The reason is that China sees blockchain as the next frontier for digital infrastructure, and considers blockchain as an important ingredient for improving smart city services. 
Table 4

Blockchain-related projects of government ministries

\begin{tabular}{lll}
\hline Government Agencies & Project & \multicolumn{1}{c}{ Remarks } \\
\hline $\begin{array}{l}\text { Ministry of Housing and Urban-Rural } \\
\text { Development }\end{array}$ & Interconnecting provident fund & $\begin{array}{l}\text { Allow citizens to access the provident fund in nearly 500 } \\
\text { cities while they are relocated. }\end{array}$ \\
$\begin{array}{l}\text { China's Central Bank } \\
\text { Ministry of Public Security }\end{array}$ & $\begin{array}{l}\text { Digital currency \& electronic payment } \\
\text { Blockchain-based electronic identity }\end{array}$ & $\begin{array}{l}\text { Provide a secure identity authentication platform for } \\
\text { government and enterprise. }\end{array}$ \\
The Supreme Court of China & Blockchain-based electronic evidence & Solidify the electronic evidence collected by forensics. \\
\hline
\end{tabular}

Some of the most prominent blockchain projects at different levels are reviewed in this subsection. The blockchain applications at the central government level are summarized in Table 4, while the ones at the province and city levels are summarized in Table 5.

\subsubsection{Central government and ministries of China}

In 2016, blockchain was noted as one of the strategic frontier technologies in the "The 13th five-year plan for national informatization", which shed light on the direction for informatization in the next five years [44]. It is the first time that blockchain appeared in a key informatization guideline document at the central government level. As prices of Bitcoin and other digital currencies rose rapidly, the Chinese central government always took a clear restraint attitude on cryptocurrencies. In 2017, seven Chinese government agencies including the Central Bank of China jointly issued "Announcement on Preventing the Risk of Financing of Token Issuance" to warn the investment risk brought by the issuance of cryptocurrencies [17]. In 2018, Ministry of Industry and Information Technology released a white paper "China blockchain technology and application development", which indicated the technology path of blockchain and the future direction of blockchain standardization [33].

In October 2019, China's top leadership attended a group study focusing on blockchain. A statement was released after the meeting, which stressed that China's financial sector will uptake blockchain as an important tool to catch up and compete with the leading international financial peers. It added that blockchain-enabled applications shall also be extended to digital assets trading, digital economy, digital finance, supply chain finance, inclusive finance, Internet of things and intelligent manufacturing [45].

Unfortunately, it has always been a fact that the regulatory supervision would fail to keep up with the pace of innovation. Especially in the case of blockchain, a lack of suitable regulations is one of the main factors hindering its large-scale rollouts in China. In order to take benefits of blockchain (e.g., transparency and immutability), the Central Bank of China supported the expansion of blockchain-enabled financial projects. At the end of December 2019, the city of Beijing started to test pilot projects within the supervision sandbox, or the Chinese version of regulatory sandbox, which is a kind of closed testing environment for developing new business models that are not supervised by existing regulations. In August 2020, Beijing, Shanghai and Shenzhen announced the pilot applications to be tested in the regulatory sandbox. The Yangtze River Delta also established a regional regulatory sandbox for enterprises to trial pilot implementations.

A number of blockchain based smart city projects have been initiated since the release of the national smart city policies [46].

(1) The Ministry of Housing and Urban-Rural Development aims to rapidly inter-connect the provident fund centers of nearly 500 cities. It intends to take advantages of data immutability of blockchain to operationalize the fund data sharing while citizens are moving across cities, which is expected to facilitate citizens' access to the provident fund in different places to a great extent [20].

(2) China's digital currency, the so-called Digital Currency Electronic Payment (DCEP), endorsed by the state, is issued by the China's central bank and currently undergoing a series of trials. DCEP is a kind of sovereign digital currency, which relies on technologies such as blockchain and electronic encryption. It has the advantages such as cost-effective, security and efficiency [35].

(3) Electronic identity, based on blockchain, is a digital mark issued and managed by the citizen network identification system of the Ministry of Public Security. It can identify a person on the site or remotely, without 
Table 5

Blockchain-related projects in different provinces and cities

\begin{tabular}{|c|c|c|c|}
\hline \multirow[t]{2}{*}{ Province/City } & \multicolumn{3}{|c|}{ Pilot Applications } \\
\hline & Application & Agency & Remarks \\
\hline \multirow[t]{4}{*}{ Beijing } & $\begin{array}{l}\text { Customs clearance } \\
\text { (Beijing-Tianjin-Hebei) }\end{array}$ & Beijing Municipal Commerce Bureau & $\begin{array}{l}\text { Improve efficiency of cross-border } \\
\text { trade at customers of the international } \\
\text { air hub }\end{array}$ \\
\hline & $\begin{array}{l}\text { Blockchain-based paperwork } \\
\text { platform for SMEs }\end{array}$ & Beijing Financial Supervision & $\begin{array}{l}\text { Simplify the paperwork that merchants } \\
\text { need to fill }\end{array}$ \\
\hline & Real estate registration & $\begin{array}{l}\text { Municipal Commission of Planning } \\
\text { and Natural Resources }\end{array}$ & $\begin{array}{l}\text { Reduce unnecessary on-site visits for } \\
\text { citizens }\end{array}$ \\
\hline & Electronic certificates and licenses & Beijing Municipality Administration & $\begin{array}{l}\text { Reduce costs and save time in dealing } \\
\text { with government service }\end{array}$ \\
\hline Xiong'an, Hebei & Digital Xiong'an & $\begin{array}{l}\text { Industrial and Commercial Bank of } \\
\text { China }\end{array}$ & $\begin{array}{l}\text { The first blockchain based requisition } \\
\text { and demolition fund management in } \\
\text { China }\end{array}$ \\
\hline Nanjing, Jiangsu & Time bank for elderly care & Residential Community & $\begin{array}{l}\text { The first time bank for depositing } \\
\text { volunteering services for elderly care } \\
\text { in China }\end{array}$ \\
\hline \multirow[t]{4}{*}{ Shanghai } & Products tractability & Municipal Commission of Commerce & $\begin{array}{l}\text { Provide the product traceability to } \\
\text { ensure product safety }\end{array}$ \\
\hline & Inter-company reinsurance platform & $\begin{array}{l}\text { Shanghai Insurance Regulatory } \\
\text { Bureau }\end{array}$ & Provide credibility check for insurance \\
\hline & Social credit system & $\begin{array}{l}\text { Municipal Commission of } \\
\text { Construction }\end{array}$ & $\begin{array}{l}\text { Provide credit data through distributed } \\
\text { blockchain nodes }\end{array}$ \\
\hline & $\begin{array}{l}\text { Medicine tracing and delivering } \\
\text { platform }\end{array}$ & $\begin{array}{l}\text { Health and Family Planning } \\
\text { Commission }\end{array}$ & $\begin{array}{l}\text { Explore innovative solutions to ensure } \\
\text { medicine safety }\end{array}$ \\
\hline \multirow[t]{2}{*}{ Zhejiang } & Blockchain-based government affairs & Market Supervision Bureau & Provide transaction compliance check \\
\hline & Blockchain-based municipal services & Ningbo Municipal Administration & $\begin{array}{l}\text { Provide municipal services, e.g., } \\
\text { assisting citizens to claim the power } \\
\text { failure insurance }\end{array}$ \\
\hline $\begin{array}{l}\text { Chengdu, } \\
\text { Sichuan }\end{array}$ & Blockchain-based municipal services & Chengdu Municipal Administration & $\begin{array}{l}\text { Provide municipal services, e.g., } \\
\text { volunteering platform, intellectual } \\
\text { property alliance chain, and supply } \\
\text { chain finance }\end{array}$ \\
\hline \multirow[t]{2}{*}{$\begin{array}{l}\text { Shenzhen, } \\
\text { Guangdong }\end{array}$} & i-Shenzhen & Shenzhen Municipal Administration & $\begin{array}{l}\text { Provide blockchain based certificates } \\
\text { and licenses verification }\end{array}$ \\
\hline & Electronic invoice System & Shenzhen Taxation Bureau & $\begin{array}{l}\text { The first blockchain based electronic } \\
\text { invoice system in China }\end{array}$ \\
\hline
\end{tabular}

disclosing any sensitive information. On the one hand, it links various government systems to provide "onestop" services, and improve the efficiency of the provided services. On the other hand, it not only helps governments to link the management of human resources, finance, and projects, but also provides enterprises with a secure identity authentication platform [16].

(4) The Supreme Court of China intends to improve the storage of electronic evidence by utilizing blockchain. A new system has been developed that integrates local courts, notary offices and judicial authentication centers to strengthen the authentication of electronic evidence and streamline the evidence reviewing procedures. An electronic evidence platform has been built in Zhejiang to solidify the electronic evidence collected by forensics to support the judicial process [30].

\subsubsection{Provinces and cities of China}

Beijing Beijing aims to equip the city with "new infrastructure" and trial the blockchain technology in digital government services. In 2020, Beijing released a blue book on "Innovative Applications of Blockchain in the Municipal Government Services", which asserts the necessity, feasibility and significance of introducing blockchain 
into the field of government services [4]. Twelve pilot applications are showcased in the blue book, some of which are explained below.

(1) The customs clearance facilitation in Beijing-Tianjin-Hebei Region is one of the twelve pilot applications featured in the blue book. The project is led by the Beijing Municipal Commerce Bureau, which aims to use the blockchain based logistics platform for speeding up customs clearance operations and improving efficiency of cross-border trade in the international air hub.

(2) The Beijing Financial Supervision introduces a blockchain-based service platform for SMEs. The platform decreases the waiting time for opening a bank account by $40 \%$, and simplifies the documents that merchants need to file by $80 \%$.

(3) The Beijing Municipal Commission of Planning and Natural Resources created a blockchain-based real estate registration system. The registration system is built with the idea to provide "one-stop" online services, which has resulted in a reduction of up to 100,000 on-site visits of citizens.

(4) The Beijing Municipality Administration introduced blockchain based electronic certificates and licenses. By uploading frequently used electronic certificates and licenses to the blockchain-based system, e.g., identity card, social security insurance, and business license, 253 corporate-related issues and 65 personal ones can be managed without the need of paper certificates. This not only reduces costs, but also saves time in dealing with government services.

Xiong'an, Hebei Following the government's blueprint, the project "digital Xiong'an, smart new district" was initiated in Xiong'an, which is now a leading smart city in Hebei. Xiong' an branch of Industrial and Commercial Bank of China formulated a blockchain plan to integrate governmental and financial services, which can augment the collaborative advantages. For example, Xiong'an and the Industrial and Commercial Bank of China jointly released a blockchain platform for managing requisition and demolition funds of old buildings in Xiong' an. This is the first such kind of blockchain application for the requisition and demolition management in China. Utilizing the blockchain features of traceability and immutability, the platform empowers Xiong'an to innovate the government services to ensure the transparency and fairness of the demolition funds [42].

Nanjing, Jiangsu In order to respond to the challenges of an aging society, Nanjing put forward a blockchainbased time bank of elderly-care service. The concept of time bank is to encourage volunteers to provide services, e.g., the elderly care, and store the service time according to certain standards. When volunteers themselves need it, they can withdraw the accumulated service time and exchange them for the services they need. The essence of the time bank concept is "time for time" which can be colloquially summarized as "all for one, one for all". The first time bank pilot was launched in Zhaoyuan residential community in Nanjing, which stores the volunteering time on blockchain and also facilitates exchange of time coins in Alipay's time bank. The government of Nanjing plans to integrate the "time bank" into its service portfolio following a full trial of the pilot [47].

Shanghai

(1) Shanghai Municipality Commission of Commerce adopts blockchain to enhance reconstruction of supply chains. In November 2018, the "Yangtze River Delta Products Traceability Alliance" was officially established. It aimed at solving problems in the traditional traceability system, improving the traceability efficiency and ensuring products safety. Later in the same month, the first China's International Import Expo was held in Shanghai using blockchain to ensure the safety of the food used in the event [11].

(2) Under the leadership of the Shanghai Insurance Regulatory Bureau, a number of insurance agencies, reinsurance agencies and financial technology institutions collaborated to build an inter-company reinsurance trading platform using blockchain. The Shanghai Insurance Exchange has developed and constructed a blockchain platform for credibility check, which provides the foundation for the insurance industry to build a transaction ecosystem and improves transaction accuracy.

(3) In 2019, the Shanghai social credit system for construction companies was deployed based on blockchain, which was awarded in the Shanghai blockchain application innovation competition, reflecting the important role of blockchain in the construction of social credit. The social credit system was also extended to be applied for the sharing market information in Shanghai. Each alliance organization can access credit data through distributed blockchain nodes to achieve transparency, traceability and auditability. 
(4) Shanghai Health and Family Planning Commission carried out a dedicated research project to explore innovative solutions for medicine safety and delivery based on a blockchain-enabled tracing and delivering platform for medicine.

Zhejiang Zhejiang implemented a blockchain application for government affairs, with emphasis on electronic bills, judicial certificates and market supervision. Entrusted by the State Administration for Market Regulation, the Market Supervision Bureau of Zhejiang has been testing an online transaction monitoring platform, which is expected to be rolled out in other provinces after the trial. The platform adopts the alliance chain technology, takes various judicial agencies as information nodes, and preserves electronic evidence for suspected commodities. The platform is designed to achieve almost real-time compliance supervision for market transactions [18].

The city of Ningbo strives to become a blockchain powerhouse in Zhejiang. For example, Ningbo Power Supply created a blockchain platform for insurance. It is the first such application that assists customers to claim the power failure insurance in Zhejiang. The Ningbo blockchain centre and the digital currency research institute of People's Bank of China are jointly undertaking a national key project on blockchain-based platform for trade finance. Ningbo also cooperated with Huawei and the Zhejiang Provincial Bureau of Cultural Relics to carry out a research program for social-cultural relics based on blockchain [43].

Chengdu, Sichuan Chengdu, a central city of China, has the ambition to build a "full coverage, full information, and full services" digital infrastructure to support the deep integration of big data, artificial intelligence and blockchain to provide one-stop services, such as business incubation, business docking, corporate investment, and financing.

In January 2019, the blockchain special committee of Chengdu issued a report on blockchain, calling for acceleration of the development of blockchain technology. Driven by a series of policies, Chengdu has been cultivating blockchain applications in various fields [19], which are reviewed as follows.

(1) Volunteering. A blockchain volunteering platform focusing on people's livelihood services was established in Chengdu.

(2) Intellectual property protection. Several companies jointly initiated and established the first national intellectual property alliance chain in the Chengdu high tech Zone.

(3) Supply chain finance. Financial institutions are now more confident to provide short-term liquidity supports for small enterprises in supply chains. Thanks to the data immutability of blockchain, it is much easier for financial institutions to evaluate loan risks and collaterals.

Shenzhen, Guangdong In response to the call for "one-stop" services, Shenzhen launched an application called "i-Shenzhen" that integrates the government affairs and services on a blockchain platform focusing on electronic certificates and licenses [7]. "i-Shenzhen" has now launched 24 types of commonly used electronic certificates and licenses, such as identity, social security, business license and driver license, which provide great convenience for citizens to do business online. Those electronic certificates and licenses not only conveniently help in ascertaining "who is who", but also solve the trust problems. This is materialized by building a series of new credit-related ecosystem for identity proof including credit generation, credit authorization, and credit economy.

Shenzhen Taxation Bureau is committed to building the country's first blockchain electronic invoice system [29]. The blockchain based electronic invoice fulfils the encryption processing of invoices as well as transactions synchronization. It also combines invoicing and reimbursement processes by integrating fund flow and invoice flow. Due to its advantages of immutability, transparency, traceability and privacy, it was soon applied to other fields including rail transit, financial insurance and real-estate sales. In particular, during the recent pandemic, the blockchain electronic invoices gained more attention and successfully entered the healthcare system with its contactless advantage.

\section{Remarks on the reviewed applications}

In this section, we present our remarks on the reviewed blockchain initiatives of the three countries, and summarize the blockchain applications in Table 6 and Table 7 . 
Table 6

Fields of blockchain applications of central/federal governments

\begin{tabular}{|c|c|c|c|}
\hline Fields & South Korea & United States & China \\
\hline \multirow{2}{*}{$\begin{array}{l}\text { Digital evidence } \\
\text { and forensic }\end{array}$} & $\checkmark$ & $x$ & $\checkmark$ \\
\hline & National Police Agency & & Supreme Court of China \\
\hline \multirow[t]{2}{*}{ Traceability } & $\checkmark$ & $x$ & $x$ \\
\hline & $\begin{array}{l}\text { Rural Development } \\
\text { Administration }\end{array}$ & & \\
\hline \multirow[t]{3}{*}{ Electronic identity } & $\checkmark$ & $x$ & $\checkmark$ \\
\hline & Ministry of Health and Welfare; & & Sharing provident fund data; \\
\hline & $\begin{array}{l}\text { National Election Commission; } \\
\text { etc. }\end{array}$ & & Ministry of Public Security; etc. \\
\hline \multirow[t]{3}{*}{ Supply chain } & $\checkmark$ & $x$ & $x$ \\
\hline & $\begin{array}{l}\text { Ministry for Food, Agriculture, } \\
\text { Forestry, and Fisheries; }\end{array}$ & & \\
\hline & $\begin{array}{l}\text { Ministry of Oceans and } \\
\text { Fisheries; etc. }\end{array}$ & & \\
\hline \multirow[t]{3}{*}{ Documentation } & $\checkmark$ & $x$ & $x$ \\
\hline & $\begin{array}{l}\text { Ministry of Land, } \\
\text { Infrastructure, and Transport; }\end{array}$ & & \\
\hline & Ministry of Foreign Affairs; etc. & & \\
\hline \multirow[t]{3}{*}{ Cryptocurrency } & $x$ & $\checkmark$ & $\checkmark$ \\
\hline & & Internal Revenue Service; & DCEP \\
\hline & & $\begin{array}{l}\text { Securities and Exchange } \\
\text { Commission; etc. }\end{array}$ & \\
\hline
\end{tabular}

\subsection{Remarks on blockchain applications in South Korea}

The central government of South Korea assesses that blockchain is a disruptive technology with huge potentials. Thus, South Korea actively applies blockchain in its public services and seeks to be a blockchain leader. However, positive results are needed to show that blockchain can solve social issues while making public services efficient, e.g., to validate sustainability and effectiveness of those pilot projects. For that reason, the implementation of blockchain for public services is a valuable opportunity for blockchain-related enterprises. As once validated, the government of South Korea will support more blockchain-related projects via policies and governmental funds.

In the province level, this paper showed a number of very impressive applications that fit the characteristics of each district. For example, Seoul, where most workers gathered in Korea, supported laborers with the blockchainbased contract, which is very promising in protecting workers and for them to receive their rightful welfare benefits. Jeju Island is a forerunner of eco-friendly policies, which in fact began with the project that managed circulation of used EV batteries through a blockchain-based platform. Another interesting application is cryptocurrency as a local voucher in Jeollabuk, which is highly welcomed by tourists and local merchants. These projects have shown strong signs of addressing local public interests, which in time can be extended to other areas of application.

\subsection{Remarks on blockchain applications in the United States}

Several states led the blockchain applications into their public services ahead of other states. Not unexpectedly, however, some states faced problems in achieving the desired degree of efficiency and effectiveness in their use of blockchain to deliver public services. The example discussed for the state government of Delaware explained how the project faced inefficiency issues that led to its termination. However, the key issues were in technology readiness, which we believe will be soon overcome.

Some states and cities, e.g., Illinois and New York City, among others, expressed interest in blockchain. We can anticipate that if pilot programs being led in these areas are successful, more state governments and institutions will join the movement. 
Table 7

Fields of blockchain applications of provincial/state governments

\begin{tabular}{|c|c|c|c|}
\hline Fields & South Korea & United States & China \\
\hline \multirow{3}{*}{$\begin{array}{l}\text { Transparency of } \\
\text { governance }\end{array}$} & $\checkmark$ & $x$ & $\checkmark$ \\
\hline & Electronic contract; & & Xiong'an demolition fund management \\
\hline & Water quality system; etc. & & \\
\hline \multirow[t]{3}{*}{ Traceability } & $x$ & $x$ & $\checkmark$ \\
\hline & & & Yangtze River Delta traceability alliance; \\
\hline & & & $\begin{array}{l}\text { Shanghai tracing and delivering platform for } \\
\text { medicine; etc. }\end{array}$ \\
\hline \multirow[t]{3}{*}{ Documentation } & $\checkmark$ & $\checkmark$ & $\checkmark$ \\
\hline & $\begin{array}{l}\text { Document management } \\
\text { platform }\end{array}$ & Property title registration & Beijing Financial Supervision; \\
\hline & & & Real estate registration; etc. \\
\hline \multirow[t]{3}{*}{ Cryptocurrency } & $\checkmark$ & $\checkmark$ & $x$ \\
\hline & $\begin{array}{l}\text { S-Coin; Cryptocurrency in } \\
\text { Jeollabuk; etc. }\end{array}$ & Wyoming digital assets-existing law; & \\
\hline & & Berkeley municipal bond; etc. & \\
\hline \multirow{2}{*}{$\begin{array}{l}\text { Electronic } \\
\text { identity }\end{array}$} & $\checkmark$ & $x$ & $\checkmark$ \\
\hline & $\begin{array}{l}\text { Seoul Citizen Card; } \\
\text { Decentralized Identifier; } \\
\text { etc. }\end{array}$ & & i-Shenzhen \\
\hline \multirow[t]{3}{*}{ Recording } & $\checkmark$ & $\checkmark$ & $\checkmark$ \\
\hline & $\begin{array}{l}\text { Tracking carbon usage; } \\
\text { EV battery management; } \\
\text { etc. }\end{array}$ & Delaware Public Archives; & Shenzhen electronic invoice system \\
\hline & & Illinois energy usage; etc. & \\
\hline \multirow[t]{2}{*}{ Healthcare } & $\checkmark$ & $\checkmark$ & $\checkmark$ \\
\hline & AI-assisted diagnosis & Health status check & Nanjing time bank \\
\hline \multirow[t]{2}{*}{ Supply chain } & $x$ & $x$ & $\checkmark$ \\
\hline & & & Customs clearance facilitation \\
\hline \multirow[t]{2}{*}{ Credibility } & $x$ & $x$ & $\checkmark$ \\
\hline & & & Shanghai social credit system \\
\hline \multirow{2}{*}{$\begin{array}{l}\text { Digital evidence } \\
\text { and forensic }\end{array}$} & $x$ & $x$ & $\checkmark$ \\
\hline & & & Market Supervision Bureau of Zhejiang \\
\hline \multirow[t]{3}{*}{ Insurance } & $x$ & $\checkmark$ & $\checkmark$ \\
\hline & & Insurance document management & Shanghai insurance exchange; \\
\hline & & & Power failure insurance claim; etc. \\
\hline \multirow{3}{*}{$\begin{array}{r}\text { Intellectual } \\
\text { property }\end{array}$} & $x$ & $x$ & $\checkmark$ \\
\hline & & & Zhejiang Provincial Bureau of Cultural Relics; \\
\hline & & & $\begin{array}{l}\text { National intellectual property alliance in } \\
\text { Chengdu; etc. }\end{array}$ \\
\hline
\end{tabular}

\subsection{Remarks on blockchain applications in China}

With its origin in digital currency, blockchain has not only been popular in the financial field, but also has been introduced into the field of government affairs and been expanded to other services. Presently, the blockchain's role in China is mainly about recording transaction data or verifying documents. It can be expected that blockchain gradually integrates with more activities of industries and organizations.

Digital assets are the cornerstone of digital economies. As discussed in the paper, more and more virtualization and digitalization produced blockchain-like assets represented by cryptocurrencies and tokens. Asset digitization can lead to faster processing in trading as well as supporting credibility through smart contracts. It also brings about 
other benefits including reducing the transaction costs, improving the efficiency of governments/enterprises, and protecting personal assets.

Supervision technology can conduct the real-time supervision of transaction data. This can be achieved by exploiting key characteristics of blockchain, including security, transparency, immutability and traceability. Powerful supervision technology can be used in different fields, which is conducive to the supervision of the market and government over socio-economic affairs.

In the field of governance, regions including Beijing, Shenzhen, Chengdu, Xiong'an and Zhejiang have implemented applications in varied aspects of government services. Examples reviewed include: urban construction and management, people's livelihood service, data sharing, electronic license and bill, digital identity, business cooperation, judicial deposit and fund supervision.

In the health field, Shanghai used health and medical data to promote medical management to solve the problem of 'Information Island' and improve the utilization rate of medical resources.

In the financial field, Beijing, Xiong' an and Chengdu used electronic enterprise identity to build financial service platforms. Regarding the financial insurance, Ningbo and Shanghai developed the information exchange system of credit. Shanghai created a digital asset exchange that connects different blockchain systems, leading to a shift in the way of information sharing.

Applications of blockchain in industry have been involving areas, such as manufacturing, supply chain management or cross-border trade. Shanghai integrates financial data and product data in the Yangtze River Delta to achieve food traceability and safety assurance.

In the field of logistics, Beijing, Ningbo, and Chengdu improved the efficiency of cross-border trade and achieved higher reliability in the storage of information from customs, ports, taxation and freight.

\section{Conclusions}

The paper does not aim at providing an exhaust survey on all the blockchain related projects. Instead, the paper focuses on studying the governments' attitude over the blockchain developments among South Korea, the United States and China by reviewing their core blockchain policies and sampling their high-profile blockchain pilots.

There are two noteworthy features of smart city projects in China comparing to those ones in South Korea and the United States: technology-centered and top-down driven. China is keen on building smart cities based on the latest technologies, e.g., artificial intelligence, 5G, Internet of things, and cloud computing. Secondly, most of the smart city projects in China are driven by the high-level governments or ministries. The local governments then follow the upper-layer patterns. This top-down scheme is quite different from the design philosophy of smart cities in South Korea and the United States.

Despite the differences among the three countries, pioneering applications have already shown that blockchain's potentials in tackling challenges faced by traditional systems. For the next step, we will need to be aware of the following challenges. First, blockchain has the promise to provide data traceability and immutability for data that are recorded on the chain. However, the data authenticity before being recorded on blockchain is still a problem. Thus, some methods that guarantee the information authenticity before the data being added on chain are needed. Second, the transaction speed of blockchain system is much lower than the traditional clearing system, which is due to the features of chained structure and distributed consensus. Thus, swift consensus protocols need to be introduced. Third, blockchain is relatively new and is still evolving, so the unclear effects blockchain may bring in, the potential exposure of sensitive information, and the costs of employing blockchain, need more rigorous studies.

\section{Acknowledgements}

The authors would like to express their gratitude to the editors and anonymous reviewers for their careful reading of the manuscript and offering insightful comments. 


\section{Conflict of interest}

None to report.

\section{Funding}

This research was funded by the NSFC (61902332), CUHK-Shenzhen URA, Shenzhen STIC (JCYJ20170818103 636337, JCYJ20180508162604311 and ZDSYS20170725140921348), and National Key R\&D Program of China (2018YFC1603300)

\section{References}

[1] M. An and Y. Park, Legal system of blockchain and domestic and foreign blockchain legal system-focusing on industrial revitalization, Journal of Digital Convergence 17(10) (2019), 67-75.

[2] M. Attaran and A. Gunasekaran, Applications of Blockchain Technology in Business: Challenges and Opportunities, Springer Nature, 2019.

[3] A. Bansal, C. Garg and R. Padappayil, Optimizing the implementation of COVID-19 "immunity certificates" using blockchain, Journal of Medical Systems 44(9) (2020), 1-2. doi:10.1007/s10916-020-01628-0.

[4] Beijing Municipal Bureau of Government Service and Management, The Blue Book on the Innovative Blockchain Applications in the Field of Government Services in Beijing, 2021, [Online]. Available http://english.beijing.gov.cn/investinginbeijing/biz_environment/biz_notices/ 202009/t20200916_2061030.html [Accessed 10 November 2021].

[5] S. Blemus, Law and blockchain: A legal perspective on current regulatory trends worldwide, Revue Trimestrielle de Droit Financier (Corporate Finance and Capital Markets Law Review) 4 (2017).

[6] J. Caytas, Blockchain in the US regulatory setting: Evidentiary use in Vermont, Delaware, and elsewhere, Columbia Science \& Technology Law Review (2017).

[7] V. Chaurasia, A. Yunus and M. Singh, An overview of smart city: Observation, technologies, challenges and blockchain applications, in: Blockchain Technology for Smart Cities, Springer, Singapore, 2020.

[8] CNBC, Treasury Secretary Steven Mnuchin Speaks with CNBC's Squawk Box, 2019, [Online]. Available https://www.cnbc.com/2019/ 07/18/first-on-cnbc-cnbc-transcript-treasury-secretary-steven-mnuchin-speaks-with-cnbcs-squawk-box-today.html [Accessed 10 November 2021].

[9] S. Delahunty, Developments and adoption of blockchain in the US federal government, Forbes Technology Council (2018).

[10] P. Duy, D. Hien, D. Hien and V. Pham, A survey on opportunities and challenges of blockchain technology adoption for revolutionary innovation, in: Proceedings of the Ninth International Symposium on Information and Communication Technology, Danang, 2018 , pp. $200-207$. doi:10.1145/3287921.3287978.

[11] A. Erokhin, K. Koshechkin and I. Ryabkov, The distributed ledger technology as a measure to minimize risks of poor-quality pharmaceuticals circulation, PeerJ Computer Science 6 (2020), e292. doi:10.7717/peerj-cs.292.

[12] L. Farmer, Berkeley's Bold Bet on Bitcoin, 2018, [Online]. Available https://www.governing.com/archive/gov-berkeley-bitcoincryptocurrency.html [Accessed 10 November 2021]

[13] Federal Reserve Bank of Boston, Beyond Theory, Getting Practical With Blockchain [White Paper], 2019.

[14] Grand View Research, Blockchain Technology Market Size Report, 2021-2028, 2021, [Online]. Available https://www.grandviewresearch. com/industry-analysis/blockchain-technology-market [Accessed 10 November 2021].

[15] J. Heminway and A. Sulkowski, Blockchains, corporate governance, and the lawyer's role, Wayne Law Review 65 (2019), 17.

[16] H. Hou, The application of blockchain technology in E-government in China, in: International Conference on Computer Communication and Networks (ICCCN), Vancouver, 2017.

[17] J. Hou, C. Wang and S. Luo, How to improve the competiveness of distributed energy resources in China with blockchain technology, in: Technological Forecasting and Social Change, Vol. 151, 2020.

[18] L. Hou, R. Liao and Q. Luo, IoT and blockchain-based smart agri-food supply chains, in: Handbook of Smart Cities, Springer, Cham, 2020.

[19] S. Hsu and J. Li, Online consumer credit, online supply chain finance, and Internet banks, in: China's Fintech Explosion, Columbia University Press, 2020

[20] Q. Hu and Y. Zheng, Smart city initiatives: A comparative study of American and Chinese cities, Journal of Urban Affairs (2020), 1-22.

[21] S.J. Hughes, Property, agency, and the blockchain: New technology and longstanding legal paradigms, Wayne Law Review 65 (2019), 57.

[22] A. Irrera and J. McCrank, Wall Street finds blockchain hard to tame after early euphoria, Thomson Reuters, 2019, [Online]. Available https:// www.reuters.com/article/us-blockchain-finance-focus/wall-street-finds-blockchain-hard-to-tame-after-early-euphoria-idUSKCN1UB0YV [Accessed 10 November 2021].

[23] N. Kang, Legal issue and Regulatory Framework of Blockchain in Korea, Korea Policy Center for the Fourth Industrial Revolution, 2019, [Online]. Available https://kpc4ir.kaist.ac.kr/index.php?mid=kpc4ir_03_01_01\&document_srl=1725 [Accessed 10 November 2021].

[24] L. Koperski, Why the renewable energy credit market needs standardization, Washington Journal of Law, Technology \& Arts 13 (2017), 69. 
[25] Korea Bizwire, Busan Turns to Blockchain Technology for Water Supply System, ICT Trend, 2020, [Online]. Available http://koreabizwire. com/busan-turns-to-blockchain-technology-for-water-supply-system/159566 [Accessed 10 November 2021].

[26] Korea Institute of S\&T Evaluation and Planning, 2018 년도 예비타당성조사 보고서블록체인 중장기기술개발 사업, [2018 Preliminary Feasibility Study Report Blockchain Medium- and Long-term Technology Development Project] 2019, [Online]. Available https:// www.kistep.re.kr/reportDetail.es?mid=a10305070000\&rpt_no=RES0220190094 [Accessed 10 November 2021].

[27] Korea Internet \& Security Agency, 년 블록체인 공공선도 시범사업 공모 [2020 Blockchain Public Centered Pilot Project Contest], [Online]. Available https://www.kisa.or.kr/notice/bid_View.jsp?mode=view\&p_No=35\&b_No=35\&d_No=6995 [Accessed 10 November 2021].

[28] J. Lin, L. Mitchell, E. Crosman, D. Mendoza, M. Buchert, R. Bares, B. Fasoli, D. Bowling, D. Pataki, C. Strong and K. Gurney, CO2 and carbon emissions from cities: Linkages to air quality, socioeconomic activity, and stakeholders in the Salt Lake City urban area, Bulletin of the American Meteorological Society 99(11) (2018), 2325-2339. doi:10.1175/BAMS-D-17-0037.1.

[29] F. Liu, J. Luo, X. Wu, N. Wang, S. Qin, A. Li and S. Lu, Can the issue of invoice reimbursement in China be solved completely through the integration of blockchain and IoT technology? in: The 2nd International Conference on Blockchain Technology, Hilo, 2020.

[30] T. Lu, The implementation of blockchain technologies in Chinese courts, Stanford Journal of Blockchain Law \& Policy 4 (2020), 102.

[31] L. Manning, South Korean City Installs Decentralized Identity Verification for Public Services, Bitcoin Magazine (2020), [Online]. Available https://www.nasdaq.com/articles/south-korean-city-installs-decentralized-identity-verification-for-public-services-2020-06 [Accessed 10 November 2021].

[32] R. Meyer, South Korea's 'Bit-Island,' Jeju, Redoubles Crypto Efforts After Losing Regulatory Bid, 2019, [Online]. Available www. coindesk.com/south-koreas-bit-island-jeju-redoubles-crypto-efforts-after-losing-regulatory-bid. [Accessed 10 November 2021].

[33] Ministry of Industry and Information Technology, China blockchain technology and applications development [White Paper], 2018, [Online]. Available http://www.miit.gov.cn/n1146290/n1146402/n1146445/c6180238/part/6180297.pdf [Accessed 10 November 2021].

[34] U. Nations, United Nations E-Government Survey, 2021, [Online]. Available: https://publicadministration.un.org/en/Research/UN-eGovernment-Surveys. [Accessed 10 November 2021].

[35] M.A. Peters, B. Green and H. Yang, Cryptocurrencies, China's sovereign digital currency (DCEP) and the US dollar system, in: Educational Philosophy and Theory, 2020, pp. 1-7.

[36] Presidential committee on the fourth industrial revolution, People-Centered Plan for the Fourth Industrial Revolution to Promote Innovative Growth (I-KOREA 4.0), 2017, [Online]. Available https://www.4th-ir.go.kr/article/detail/220?boardName=internalData\&category=normal [Accessed 10 November 2021].

[37] K. Prewett, C. Shavers and D. Almond, Stated blockchain engagement, The Journal of Government Financial Management 68(4) (2020), 26-31.

[38] PricewaterhouseCoopers, PwC's Global Blockchain Survey, 2018, [Online]. Available www.pwc.com/gx/en/industries/technology/ blockchain/blockchain-in-business.html [Accessed 10 November 2021].

[39] C. Reyes, Autonomous business reality, Nevada Law Journal 479 (2020), forthcoming.

[40] Seoul Information Communication Plaza, 2020 Nyeon em-bo-ting (mVoting) un-yeong-sil-jeog mich chu-jin-hyeon-hwang [2020 mVoting operation result], 2020, [Online]. Available https://opengov.seoul.go.kr/public/list/10308 [Accessed 10 November 2021].

[41] A. Tinianow and C. Long, Delaware blockchain initiative: Transforming the foundational infrastructure of corporate finance, Harv. L. Sch. F. on Corp. Governance \& Fin. Reg (2017).

[42] E. Veglianti, E. Magnaghi, M. De Marco and Y. Li, Smart city in China: The state of art of xiong'an new area, in: Organizing Smart Buildings and Cities, Cham, Springe, 2021.

[43] G. Wei, C. Germinario, C. Grifa and X. Ma, Characterization of ancient building lime mortars of anhui province, China: A multi-analytical approach, Archaeometry 62(5) (2020), 888-903.

[44] J. Wu and N. Tran, Application of blockchain technology in sustainable energy systems: An overview, Sustainability 10(9) (2018), 3067. doi:10.3390/su 10093067.

[45] J. Xiao, Digital transformation in higher education: Critiquing the five-year development plans (2016-2020) of 75 Chinese universities, Distance Education 40(4) (2019), 515-533. doi:10.1080/01587919.2019.1680272.

[46] D. Xu, S. Tang and D. Guttman, China's campaign-style Internet finance governance: Causes, effects, and lessons learned for new information-based approaches to governance, Computer Law \& Security Review 35(1) (2019), 3-14. doi:10.1016/j.clsr.2018.11.002.

[47] Q. Xu, F. Liu and Z. Xiao, Research and design of the mutual aid tokenized economy structure based on blockchain technology: Taking time bank as an example, in: Proceedings of the 2020 3rd International Conference on Geoinformatics and Data Analysis, Marseille, 2020.

[48] J. Yoon, Seoul to Launch Their Own Cryptocurrency the S-Coin in 2021, 2021. [Online]. Available https://seoulz.com/seoul-to-launchtheir-own-cryptocurrency-the-s-coin-in-2021 [Accessed 10 November 2021].

[49] L. Zhang and Y. Ge, Identity authentication based on domestic commercial cryptography with blockchain in the heterogeneous alliance network, in: IEEE International Conference on Consumer Electronics and Computer Engineering (ICCECE), Guangzhou, 2021, pp. 191-195.

[50] W. Zhao, Seoul Mayor Plans \$100 Million Fund to Build Blockchain Smart City, 2018, [Online]. Available https://www.coindesk.com/ seoul-mayor-plans-100-million-fund-to-build-blockchain-smart-city [Accessed 10 November 2021]. 